\title{
Crystallization kinetics of chain extended poly(L-lactide)s having different molecular structures
}

\section{Omid Yousefzade ${ }^{\mathrm{a}, \$ *}$, Javad Jeddi ${ }^{\mathrm{a}, \mathrm{b}, \$}$, Lourdes Franco ${ }^{\mathrm{c}}$, Jordi Puiggalic, Hamid Garmabi ${ }^{\text {** }}$}

${ }^{a}$ Department of Polymer Engineering and Color Technology, Amirkabir University of Technology, Tehran, Iran

${ }^{\mathrm{b}}$ Department of Chemical and Biomolecular Engineering, University of Tennessee, Knoxville, USA

${ }^{c}$ Chemical Engineering Department and Barcelona Research Center in Multiscale Science and Engineering, Universitat Politècnica de Catalunya, Escola d'Enginyeria de Barcelona Est-EEBE, c/Eduard Maristany 10-14, Barcelona E-08019, Spain

Email addresses: O.Yousefzade (yousefzade@aut.ac.ir) and H.Garmabi (garmabi@aut.ac.ir).

*Authors to whom correspondence may be addressed.

${ }^{\S}$ Omid Yousefzade and Javad Jeddi contributed equally to this work. 


\begin{abstract}
Poly(L-lactide)s (PLLAs) with different chain structures were prepared by reactive melt processing and using Joncryl ADR as chain extender. Results of gel permeation chromatography (GPC) revealed that chain extended PLLAs had high molecular weights and two differentiated molecular weight distributions. Linear rheology was sensitive to the obtained molecular structures and revealed as the increase on the amount of chain extender gradually led to a decrease of the loss factor in the whole frequency region and to an increase of melt viscosity and both storage and loss moduli. In addition, the entanglement density increased significantly with addition of chain extender and had a significant influence on crystallization kinetics. Correlation of molecular weight, viscosity and entanglements changed the crystallinity and crystallization kinetics of chain extended PLLAs in both isothermal and non-isothermal crystallizations. Specifically, samples prepared from 1 wt-\% of Joncryl (PLLA1R) revealed the highest nucleation and the fastest crystallization rate.
\end{abstract}

Keywords: Chain extended PLLA; molecular structure; rheological properties; crystallization kinetics. 


\section{Introduction}

The rapid growth of polymeric products has increased the environmental concerns about their negative influence on our planet wherein petroleum-based polymers are known as a major pollution source of natural resources [1, 2]. In this regard, bio-renewable polymers have received consideration as a sustainable solution for developing enviro-friendly materials [3-6]. Poly(Llactide) (PLLA), an aliphatic thermoplastic polyester, provides unique characteristics such as biodegradability and biocompatibility beside high modulus, high strength and transparency. PLLA is a subject of intense research in the last decades [7-10] for both commodity and specialty applications. The versatility of the lactide monomer, derived from renewable biosources such as sugar and starch, allows designing a large variety of PLLA molecular architectures with appropriate mechanical and thermal properties for covering different applications $[8,11]$. Another advantage of PLLA is the possibility of recycling the lactide/lactic acid monomer generated during the hydrolysis process of PLLA at high temperature [12]. Despite the high potential of PLLA as a promising alternative of petroleum-based polymers, it confronts with challenging drawbacks such as low impact strength, hydrolysis and thermal degradation during processing, low gas resistance and low crystallinity [13]. Different strategies have been employed to overcome the limitations of PLLA. Blending with other polymers has received great attention since it is an easy way to improve mechanical properties, including toughness, when interfacial characteristics are conveniently controlled [14]. In addition, incorporation of nanoparticles allows also to modify the PLLA performance. Thus, the presence of nanoparticles can affect molecular dynamics and crystallization behavior, and improve permeability, conductivity, mechanical and thermal properties, degradability and other specific properties [15-23]. 
One of the drawbacks of PLLA during its melt processing is the decrease of molecular weight caused by thermal degradation [24, 25]. This mostly consists on the hydrolysis of the main chain ester bonds and the occurrence of intramolecular transesterification reactions, which lead to a back-biting depolymerization. Several alternatives have proposed to minimize the decomposition effect. Thus, peroxide-based radicals can stabilize PLLA against degradation and increase the viscosity of melted PLLA [26, 27]. Multi-functional co-agents such as triallyl isocyanurate lead also to significant improvement of the thermal stability, facilitating in addition PLLA molecular branching [28, 29]. An increase of the onset temperature of thermal degradation has also been demonstrated when chain extenders like tris(nonylphenyl)phosphite and polycarbodiimide have been added to the PLLA matrix. A similar effect has been detected using a commercially modified acrylic copolymer with epoxy functions (Joncryl ADR 4368) that is considered in the present work. During reactive extrusion, the molecular weight of PLLA increases in the presence of Joncryl, while its molecular architecture can be changed due to the formation of branches on the backbone. Molecular weight and molecular architecture are two crucial characteristics that determine the final properties of polymers such as rheological and crystallization behaviours [10, 30]. Chain branching and chain entanglements have obvious repercussions on the rheological properties and the crystallization rate of PLLA [31]. In this regard, the main objective of the present work is centered on the effect of chain extender co-agents on both viscoelastic and crystallization behaviors. 


\section{Experimental section}

\subsection{Materials}

PLLA (grade 4032D, melt flow index $7.0 \mathrm{~g} / 10 \mathrm{~min}$ at $210{ }^{\circ} \mathrm{C} / 2.16 \mathrm{~kg}$ ) was purchased from Nature Works, LLC, USA. It is a semi-crystalline polymer containing less than $2 \%$ of D-lactide units. Commercial multifunctional styrene-acrylic oligomers with epoxy functions (BASF, Joncryl ADR-4368) were used as a reactive chain extender agent.

\subsection{Sample preparation}

To prepare chain extended PLLA, different amounts of Joncryl (0, 0.25, 0.5 and 1 wt-\%) were added to the melted polymer. Samples were processed under nitrogen flow using an internal mixer (Braneber PL2200, Germany) that operates for 15 min with a rotor speed of $60 \mathrm{rpm}$ and temperature of $180{ }^{\circ} \mathrm{C}$. These situations were selected to minimize the thermal degradation of PLLA during the reactive melt processing. Chain extender was added after the five minutes of mixing and the reaction was considered completed when a plateau in torque curves was achieved. This time was measured about 15 min for the longest reaction time and therefore was applied to all samples [32]. The effect of Joncryl concentration on the evolution of the torquetime plot during reactive melt mixing in the internal mixer is shown in figure S1 in supplementary material. The first peak corresponds to the flowing of the melted PLLA. After the maximum, torque continuously decreased due to polymer degradation. This decrease stopped when Joncryl was added after a period of approximately 5 min. Moreover, a significant rise of torque was observed confirming the occurrence of a reaction between PLLA and Joncryl. Since, the torque is proportional to the viscosity, it depends on molecular weight and polymer structure. 
In this study, samples were coded as PLLAxR where $\mathrm{x}$ denotes the weight percent of used Joncryl (i.e. equals to $0,0.25,0.5$ and 1.0 wt-\%).

\subsection{Characterization}

Molecular weights and polydispersity index (PDI) were determined by gel permeation chromatography (GPC) using a liquid chromatograph (Shimadzu, model LC-8A) equipped with an Empower computer program (Waters). A PL HFIP gel column (Polymer Lab 300 x 7.5 mm) and a refractive index detector (Shimadzu RID-10A) were employed. The polymer was dissolved and eluted in 1,1,1,3,3,3-hexafluoroisopropanol (HFIP) containing CF3COONa (0.05M) at a flow rate of $0.5 \mathrm{~mL} / \mathrm{min}$ (injected volume $100 \mu \mathrm{L}$, approximate sample concentration 1.5 $\mathrm{mg} / \mathrm{mL}$ ). The number and weight average molecular weights were calculated using poly (methyl methacrylate) standards.

Isothermal and non-isothermal crystallization of samples were studied using a TA Q100 instrument. Approximately $5 \mathrm{mg}$ of the corresponding sample were put in an aluminum pan, encapsulated, heated to $200{ }^{\circ} \mathrm{C}$ (i.e . above the melting point) and led at this temperature for 3 min to erase thermal history. For isothermal crystallizations, samples were then quenched at a controlled rate of $50{ }^{\circ} \mathrm{C} / \mathrm{min}$ to the chosen isothermal crystallization temperature, $T_{c}$, ( i.e. 100, 110, 120 and $130{ }^{\circ} \mathrm{C}$ ). Crystallization required a maximum time of $45 \mathrm{~min}$, being samples subsequently heated to $200{ }^{\circ} \mathrm{C}$ at $10{ }^{\circ} \mathrm{C} / \mathrm{min}$ to determine the attained degree of crystallinity. For non-isothermal crystallizations, samples were cooled from the melt state at derermined rates (i.e. 2.5, 5, 7.5 and $\left.10^{\circ} \mathrm{C} / \mathrm{min}\right)$. Optical micrographs were taken with a Zeiss Axioskop 40 Pol light polarizing microscope equipped with a Zeiss AxiosCam MRC5 digital camera. Temperature was controlled with a Linkam system having a THMS 600 heating and freezing stage connected to an LNP 94 liquid nitrogen cooling system. 
The rheological behavior and melt viscoelastic properties of samples were studied using a rheometric mechanical spectrometer (AR-G2, TA) with a parallel plate (diameter of $25 \mathrm{~mm}$ ) under nitrogen atmosphere. All measurements were performed in the linear viscoelastic region at a temperature of $180{ }^{\circ} \mathrm{C}$, frequency range between 0.03 and $600 \mathrm{sec}^{-1}$, and strain amplitude of $1 \%$.

\section{Results and discussion}

\subsection{Molecular weight and architecture of PLLA chains}

As shown in figure S1, the observed significant increase of torque suggests the formation of long and branched chains. The increase of Joncryl concentration led to a considerable enhancement of torque values as well as a greater slope of the torque plot. This last feature agrees with the influence of Joncryl concentration on the kinetics of the chain extending reaction [33]. PLLA chains could be joined to each one of the 5-9 epoxy groups that belongs to each Joncryl molecule giving rise to highly branched structures and a remarkable increase of the viscosity of the system. For a quantitative molecular weight estimation of polymers resulting from the mixing process, GPC measurements were carried out as shown in Figure 1. The molecular weight of PLLA increased at the end of the reactive mixing process, while it decreased during processing without the additive. Thermal degradation of PLLA was effectively compensated by the addition of the chain extender. The impressive role of chain extender was detected even at a low concentration (i.e. $0.25 \mathrm{wt} \%$ ), demonstrating the degradation inhibitor role of Joncryl [24]. The molecular weight distribution plot (Figure 1b) shows two peaks that could be associated to linear and branched PLLA. Logically, the peak appearing at a shorter time (i.e. between 4.5 and $5.5 \mathrm{~min}$ ) corresponds to high molecular weights and therefore to branched chains. The area of this peak 
increased with Joncryl concentration. Furthermore, PDI was found to increase with Joncryl concentration mainly as a consequence of the great increment on the weight average molecular weight caused by the formed chain branched architecture.
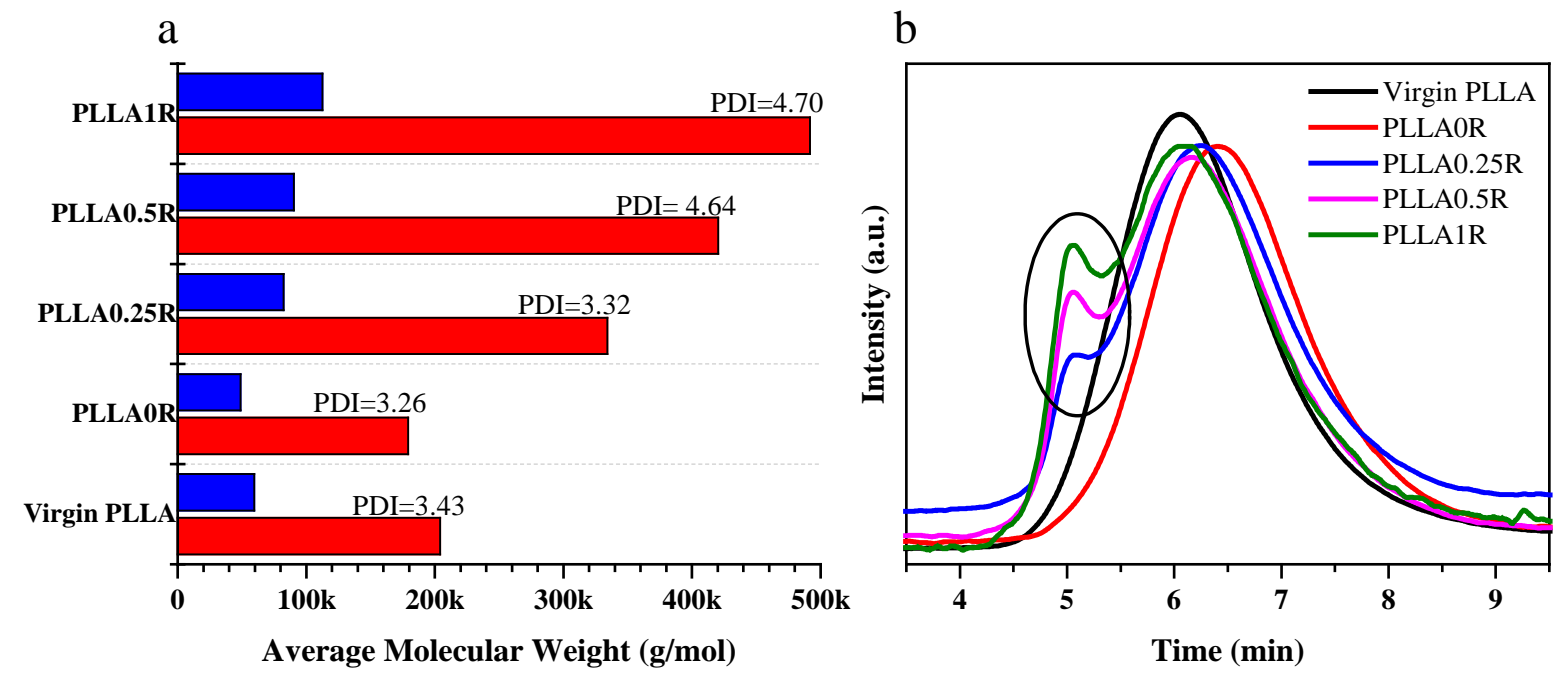

Figure 1. GPC analysis of neat PLLA and modified PLLA: a) Number (blue) and weight (red) Average molecular weight with PDI values, b) GPC curves of neat and modified PLLAs.

\subsection{Rheological analysis}

The linear viscoelastic analysis was employed to investigate the effect of chain extender on the viscoelastic properties of melted PLLA. Figure 2 depicts the variation of storage modulus ( $\left.G^{\prime}\right)$, loss modulus $\left(G^{\prime \prime}\right)$, complex viscosity $(\eta)$, and loss factor $(\tan \delta)$ of prepared samples versus frequency at different Joncryl concentration. Since rheological properties are highly sensitive to molecular weight and structure, both storage modulus and loss moduli significantly changed (Figures 2a and b) after reactive mixing of PLLA and Joncryl, as expected taking into account the increased molecular weight confirmed by GPC measurements and torque - time plots. This increase led to higher values of activation energy of flowing $\left(G^{\prime \prime}\right)$ and melt elasticity $\left(G^{\prime}\right)$ since chain entanglement density and intermolecular interactions between macromolecular chains 
clearly increased. Both shear thinning behavior and zero-shear viscosity logically increased in the whole tested frequency range. The increase of $G^{\prime}$ values revealed also cohesive network formation. The decreasing dependency of $G^{\prime}$ with $\omega$ when the Joncryl concentration increased suggests the increase of melt elasticity [30].

Figure 2c displays the variation of complex viscosity versus frequency and evidences differences between processed samples. Thus, the neat PLLA showed a Newtonian behavior at low frequency and a power law behavior at a higher frequency where viscosity decreased with increasing the frequency. The effect of Joncryl concentration on the complex viscosity plot at low frequency is noticeable and revealed that the extend of Newtonian region shortens and the shear thinning behavior becomes intensified due to increasing molecular weight and chain entanglement density. Note that the Newtonian behavior completely disappears for PLLA1R.

Loss factor $(\tan \delta)$ is a sensitive parameter for evaluating viscoelastic properties of materials. The $\tan \delta$ plots of modified samples drastically changed compared with the plot for neat PLLA (Figure 2d). The $\tan \delta$ of all samples decreased as the frequency increased due to the enhancing the elasticity of the PLLA melt at high frequency. Reactive mixing process led to the significant decreasing the $\tan \delta$ in the low frequency region as the concentration of Joncryl increased which revealed higher melt elasticity of chain extended PLLA. Variation of loss factor at low frequencies is usually related to the chain disentanglements that lead to an increase in $\tan \delta$, on the contrary a decrease of $\tan \delta$ express the inability of polymer chains to response and relax in the time window of the applied force. In summary, reactive mixing significantly decreased the $\tan \delta$ of modified PLLA samples, and moreover the observed continuous decrease against frequencies revealed that molecular chains could not be relaxed due to their high molecular weight and elasticity. Another factor which could be extracted from the tan $\delta$ curve is crossover 
frequency (at $\tan \delta$ value of 1). Figure 2d shows that the cross over frequency shifts to lower frequency in chain extended systems. This frequency reduced with addition of more chain extender which indicates the influence of chain extension on solid like behaviour of PLLA.
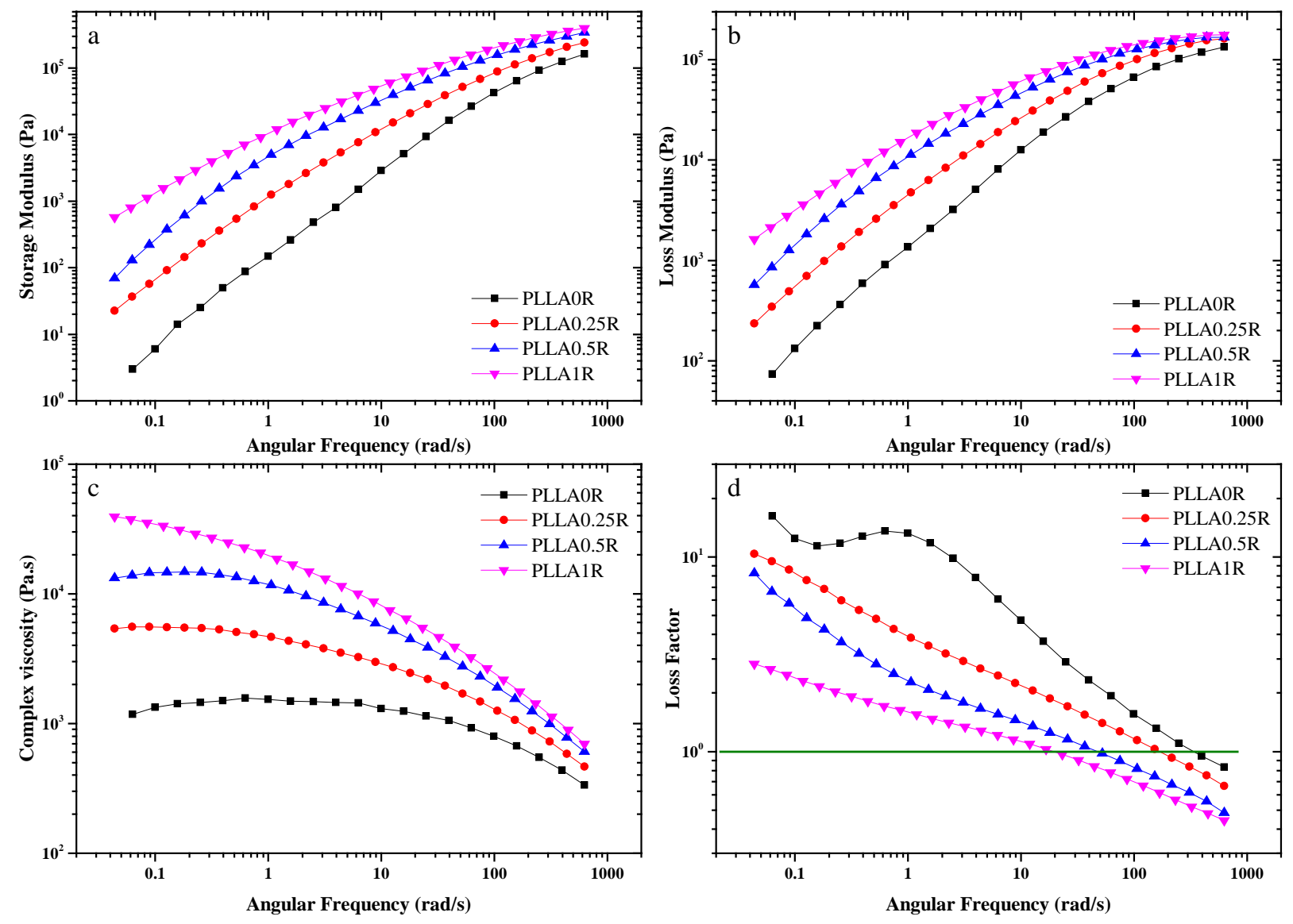

Figure 2. a) Storage Modulus, b) Loss Modulus, c) Complex viscosity, d) loss factor of neat and modified PLLAs as a function of frequency.

The relaxation spectra of samples were calculated from storage modulus $\left(G^{\prime \prime}\right)$ using the methodology proposed by Kontogiorgos along with the MATLAB code developed by Hansen. The following equation was applied [34-36]:

$$
G^{\prime \prime}(\omega)=G_{0}+\int_{0}^{\infty} H(\tau) \frac{1}{1+\omega^{2} \tau^{2}} \frac{d \tau}{\tau}
$$


where $\omega$ is the angular frequency, $\tau$ is the relaxation time, $H(\tau)$ is the relaxation spectra, and $G_{0}$ is the equilibrium modulus that equals to zero for viscoelastic liquids. The variation of $H(\tau)$ versus $\tau$ is displayed in Figure 3. The width of the spectra is related to extra-modes of relaxation due to enhanced polymer-polymer interactions, including entanglements. It seems that unlike other homopolymers, the processed PLLA has a second relaxation mechanism at longer times, which may be attributed to fluctuations and an stress release mechanism [37]. The area under the peak increased owing to the increasing Joncryl concentration. All prepared samples showed a characteristic peak at around $1 \mathrm{~s}$ that can be associated with the reptation of PLLA chains. The area of the peak in the relaxation spectra is related to zero shear viscosity, which should logically increase as the molecular weight of the sample increases. The broadening of the relaxation spectra can be associated to a cumulative effect of the relaxations attributed to different PLLA structures.

According to the graphs of figure 3, the PLLA chains relaxed following a similar pattern (i.e. PLLA0R, PLLA0.25R, and PLLA0.5R). However, the peak intensity increased with chain extender concentration which suggests a change on the molecular weight and the presence of long branches in the system. For PLLA1R sample, different relaxation spectrum observed in comparison with other samples. The change in the relaxation spectrum revealed that chain architecture of PLLA is sensitive to the concentration of Joncryl chain extender. Appearing of the shoulder around $\tau=2 \mathrm{~s}$, is an evidence of relaxation of a new highly molecular weight branched chain of PLLA that formed during reactive melt mixing. This relaxation spectra analysis was consistent with GPC results, where the appearance of a new peak in the PLLA1R sample was related to the presence of highly branched PLLA chains. 


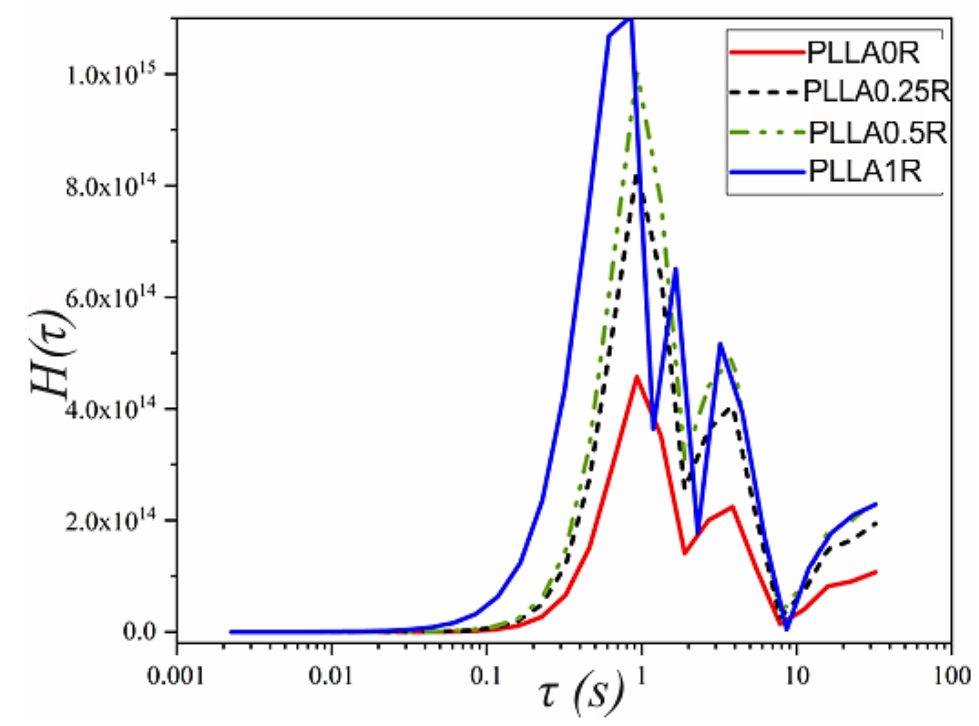

Figure 3. Comparison of relaxation spectra obtained at $180{ }^{\circ} \mathrm{C}$ to show the effect of chain extender in reactive melt mixing.

Figure 4 shows the van Gurp-Palmen ( $\delta$ vs. complex modulus) plots of the different studied samples. The phase angle $\delta$ of the neat PLLA shows a plateau near $90^{\circ}$, after which it monotonically decreased with $G^{*}$ without any transition as it is typical for a viscous behavior of linear polymers [30]. It was also found that changes on the plot shape and shift of the phase angle to values lower than $90^{\circ}$ discloses the formation of long chain branches in the system [30, 38]. The values of phase angle $\delta$ shifted towards lower degrees (far below $90^{\circ}$ ) when the concentration of Joncryl increased. In addition, no plateau region could be achieved, a feature that also proves the effect of long chain branches on the increasing melt elasticity.

Plateau modulus $\left(G_{N}^{0}\right)$ can be extracted from the van Gurp-Palmen plot and was used to calculate the entanglement density $\left(v_{e}\right)$ of samples as follows [38] :

$$
\begin{aligned}
& G_{N}^{0} \approx \lim _{\delta \rightarrow 0}\left|G^{*}(\delta)\right| \\
& v_{e}=\frac{M_{w}}{M_{e}}=\frac{M_{w}}{\rho R T / G_{N}^{0}}
\end{aligned}
$$


Where $\rho, R$ and $T$ are density of polymer, gas constant and temperature respectively. $M_{w}$ and $M_{e}$ are the molecular weight of polymer and molecular weight between the entanglements.

An extrapolation using the cubic spline method was used to calculate the $\left(G_{N}^{0}\right)$ according to equation 2. The procedure is shown in figure S2 in supplementary material for sample PLLA0R.

The values of $G_{N}^{0}$ and entanglement density of samples are presented in Table 1 . The entanglement density increased significantly after reactive mixing as discussed above. Since, the plateau of $G^{\prime}$ at high frequency $\left(G_{N}^{0}\right)$ is related to entanglement density, higher $G_{N}^{0}$ of modified PLLA revealed changing molecular structure of modified PLLA which increased the entanglement density.This observation and molecular weight distribution substantiate that the molecular structure of modified PLLA becomes different from that corresponding to neat PLLA. In the next section, crystallization behaviour of modified PLLA was attributed to this parameter which influence both the nucleation and crystal growth during the crystallization of PLLA

Table 1. Value of $G_{N}^{0}$ and the number of entanglement per chain for neat PLLA and modified PLLAs

\begin{tabular}{ccc}
\hline Sample & Plateau modulus (Pa) & Number of entanglements per chain \\
\hline PLLA0R & $2.95 \times 10^{5}$ & 11 \\
PLLA0.25R & $6.25 \times 10^{5}$ & 44 \\
PLLA0.5R & $7.21 \times 10^{5}$ & 65 \\
PLLA1R & $1.27 \times 10^{6}$ & 134 \\
\hline
\end{tabular}




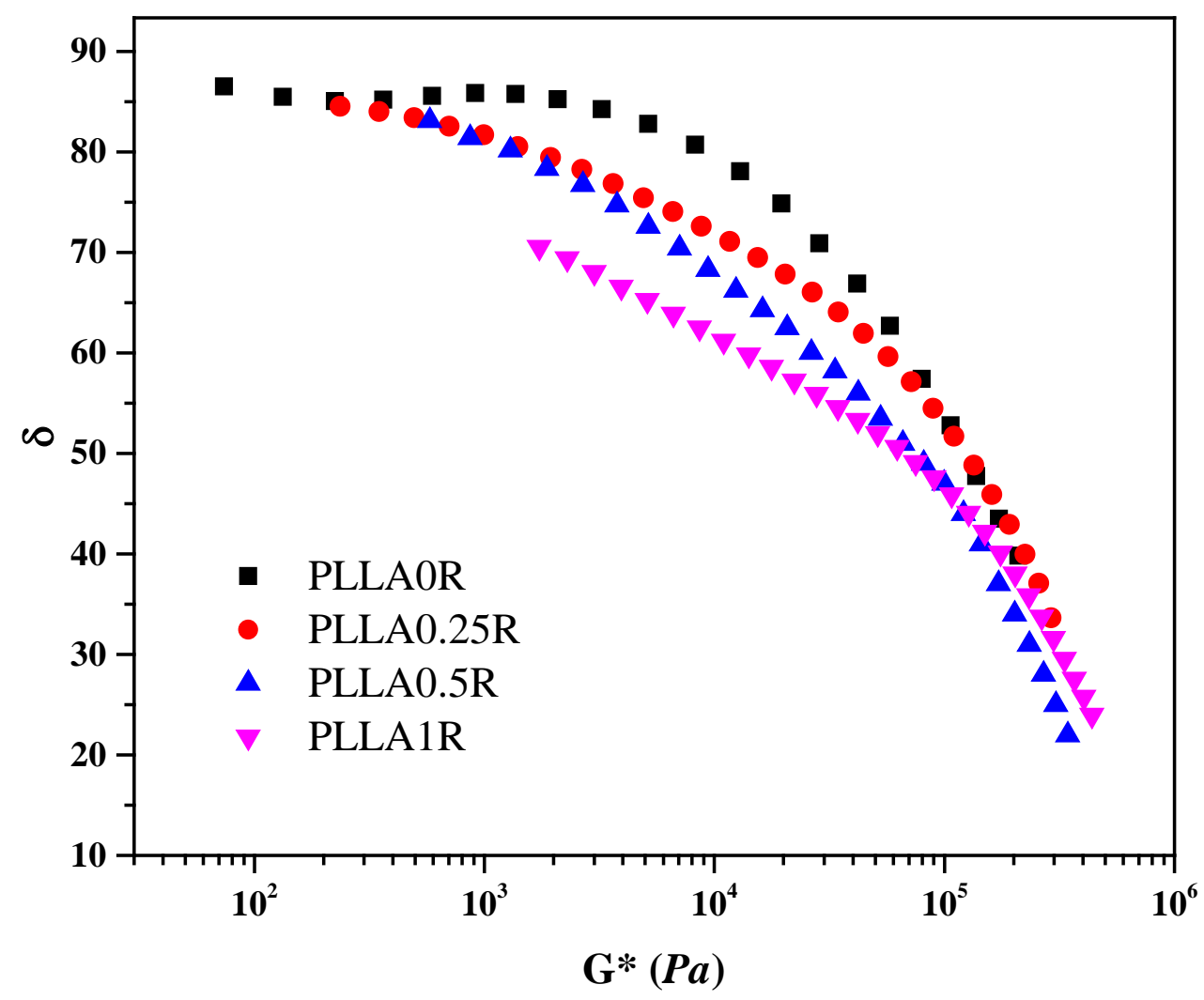

Figure 4. Evolution of the phase angle as a function of dynamic modulus (van Gurp-Palmen) for neat and modified PLLAs.

\subsection{Isothermal and non-isothermal crystallization kinetics}

Figure 5 shows the plots of the isothermal crystallization performed with samples having different concentrations of chain extender at temperatures of $100{ }^{\circ} \mathrm{C}, 110^{\circ} \mathrm{C}, 120^{\circ} \mathrm{C}$ and $130{ }^{\circ} \mathrm{C}$. Logically, the exothermic peak shifts to lower times and becomes narrower as the crystallization temperature decreases. This feature indicates a faster crystallization, which is mainly consequence of the increase on the nucleation density. Analysis of the plots allows calculating the relative degree of crystallinity through the ratio area of the exotherm up to time (i.e. $t-t_{0}$ ) divided by the total exotherm area, i.e.:

$$
\chi\left(t-t_{0}\right)=\int_{t 0}^{t}(d H / d t) d t / \int_{t 0}^{\infty}(d H / d t) d t
$$


where $\mathrm{d} H / \mathrm{d} t$ is the heat flow rate and $t_{0}$ the induction time.
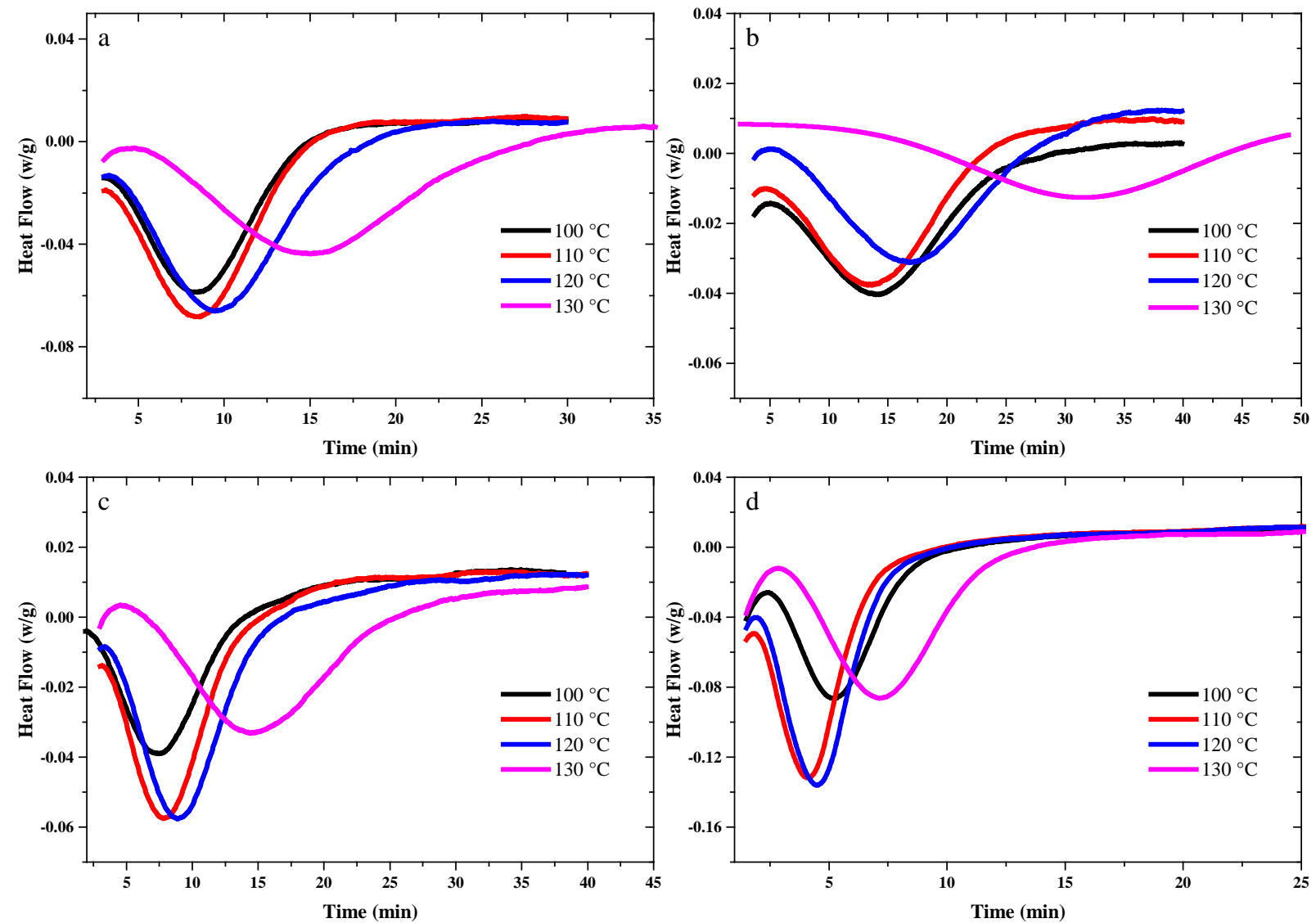

Figure 5. DSC exothermic peaks corresponding to isothermal crystallizations from the melt state performed at the indicated temperatures with: a) neat PLLA, b) PLLA0.25R, c) PLLA0.5R and d) PLLA1R

The development of crystallinity always showed a characteristic sigmoidal dependence on time, as plotted in Figure 6. The time required to complete crystallization is obviously different and becomes maximum (i.e. crystallization kinetic rate is minimum) for PLLA0.25R at all considered temperatures. The selected plotted data shows two effects:

a) The incorporation of long branches hindered crystallization. Note for example that PLLA0R crystallized clearly faster than PLLA0.25R. 
b) High entanglements density can act as nucleation sites and overcome the hindrance caused by the branched architecture. In this way, crystallization of PLLA1R becomes faster than PLLA0R. Note also that PLLA1R has the highest molecular weight and consequently a slow crystallization rate should be expected if the nucleation effect was not significant. Note also that the crystallization rate of PLLA0.5R becomes similar than that determined for PLLA0R due to the compensatory effect caused by the increase of entanglements and branches.
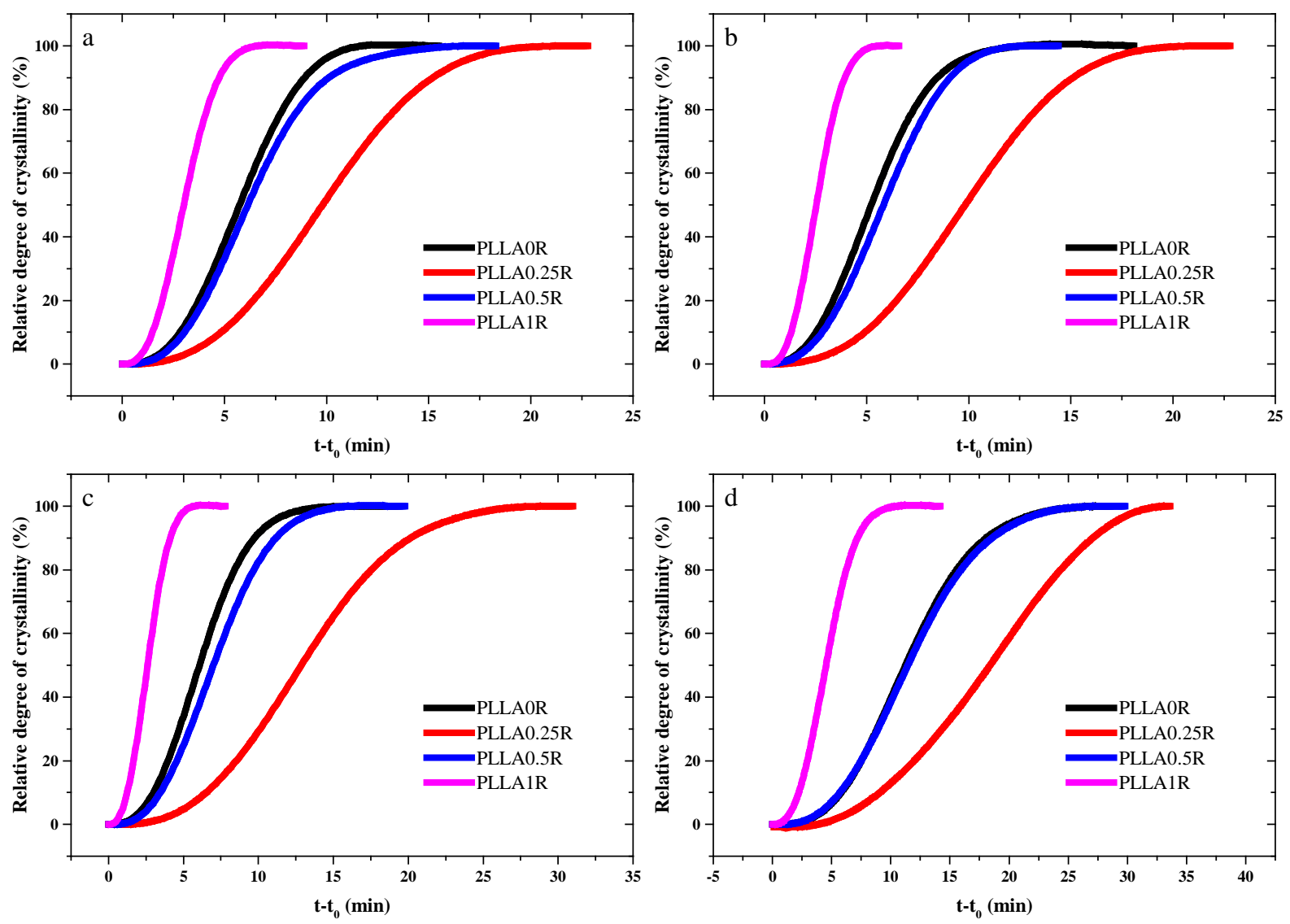

Figure 6. Relative degree of crystallization versus isothermal crystallization time for the indicated samples at temperatures of: a) $100^{\circ} \mathrm{C}(\mathrm{a}), 110{ }^{\circ} \mathrm{C}$ (b), c) $120^{\circ} \mathrm{C}$ (c) and $130{ }^{\circ} \mathrm{C}$ (d).

Crystallization data were analysed assuming the well-known Avrami equation [39] for primary crystallization:

$$
X\left(t-t_{0}\right)=1-\exp \left[-Z\left(t-t_{0}\right)\right]^{n}
$$


where $Z$ is the temperature-dependent rate constant and $n$ the Avrami exponent which value varies according to the crystallization mechanism. Both values can be deduced from the typical Avrami plots (Figure 7). A normalized rate constant, $k=Z^{1 / n}$, is usually evaluated for comparison purposes since its dimension $\left(\right.$ time $\left.^{-1}\right)$ is independent of the value of the Avrami exponent.
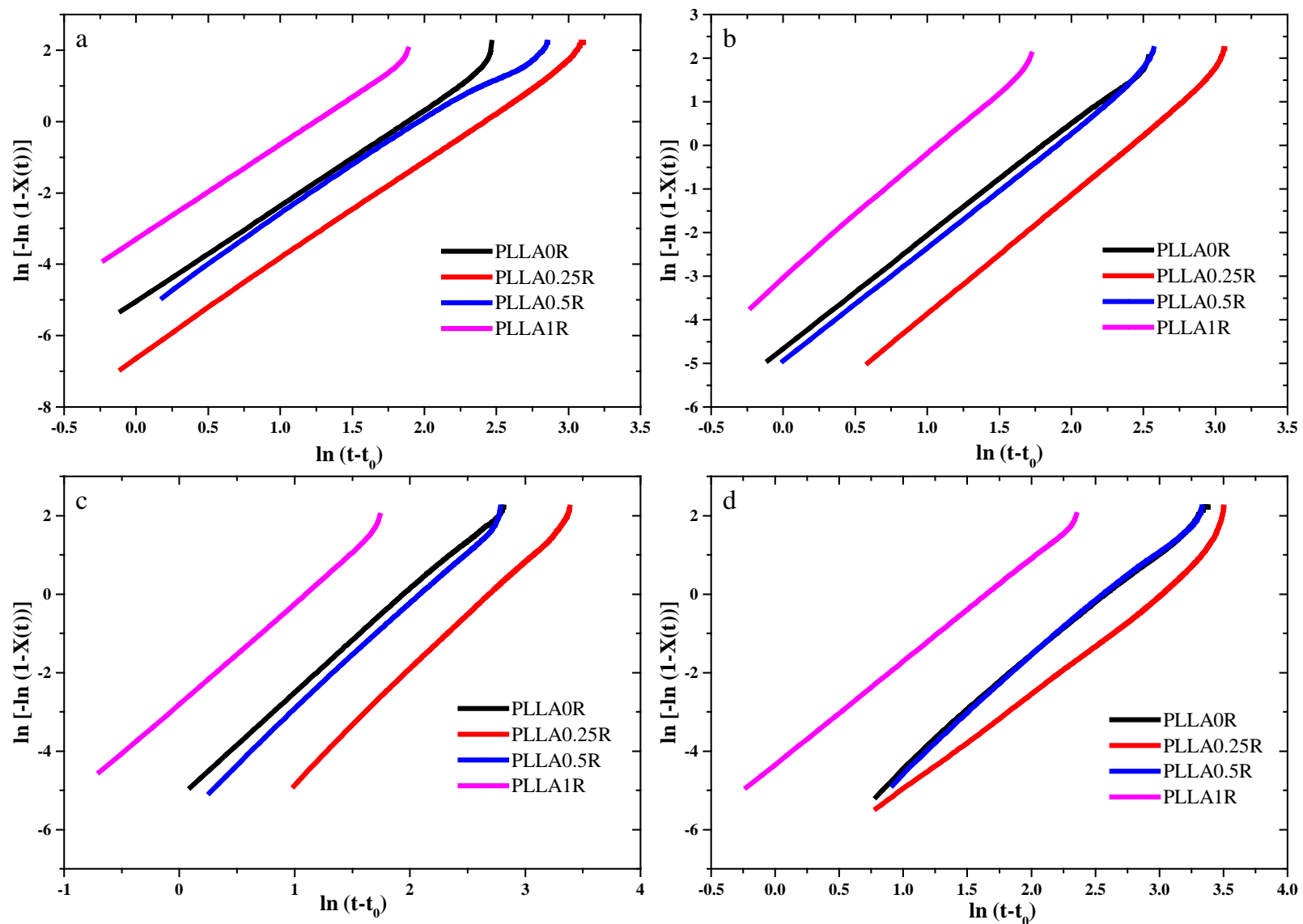

Figure 7. Avrami plots for the isothermal crystallization of the indicated samples at $100{ }^{\circ} \mathrm{C}$ (a), $110^{\circ} \mathrm{C}(\mathrm{b}), 120^{\circ} \mathrm{C}$ (c) and $130{ }^{\circ} \mathrm{C}(\mathrm{d})$.

The Avrami exponent ( $n$ ) for all samples was around 2.5-2.8, being in agreement with a three dimensional growth and a heterogeneous nucleation as also found for the neat polyester [40, 41]. Half-life crystallization time $t_{1 / 2}$ is defined as the time required getting a degree of crystallinity of 
0.5. This value can be deduced directly from Figure 6 and also can be evaluated theoretically taking into account the deduced Avrami parameters and the equation 6:

$$
t_{1 / 2}=\left(\frac{\ln 2}{K}\right)^{1 / n}
$$

The agreement between experimental and theoretical values can be considered as a validation of the Avrami analysis. Theoretical and experimental values are summarized in Table 2 for all the studied samples and confirm the suitability of the calculated parameters.

Table 2 also summarizes the values of the overall crystallization rate constant deduced from the Avrami analysis for the different samples at the four considered temperatures. These values followed obviously the opposite trend observed for the $\tau_{1 / 2}$ values (both experimental and theoretical). In summary, crystallization rates increased with decreasing temperatures and at a given temperature depended on the Joncryl content according to the previously indicated order: PLLA1R > PLLA0R PLLA0.5R > PLLA0.25R. It seems that the existence of more dense and longer branching can promote the self-nucleation in the amorphous phase of PLLA1R and accelerate the crystallization process [42].

The values of crystallization enthalpies are indicated in Table 2. These are proportional to the final degree of crystallinity. The highest enthalpy was observed for the crystallization of PLLA0R at $130{ }^{\circ} \mathrm{C}$. The lowest molecular weight and the highest linearity of PLLA0R together with high temperature chain dynamics facilitated the correct arrangement of molecular chains in the crystalline structure. Dynamics was worse when temperature decreased and consequently the crystallization enthalpy slightly decreased. Enthalpies at a given temperature decreased with the Joncryl content (i.e. PLLA0.25R > PLLA0.5R > PLLA1R) as the consequence of the increased molecular weight and the chain branching. 
It is also interesting to show that the crystallization trends changed with addition of Joncryl especially for the sample PLLA1R. Regarding the influence of Joncryl in both the nucleation and spherulite growth rates (calculated from the optical micrographs), the performance of chain extension may change at different temperatures. In low temperature (i.e. $100{ }^{\circ} \mathrm{C}$ ), the number of nuclei is too much whereas the crystal growth rate is limited. This phenomenon is highly dependent on molecular structure of PLLA which determine the nucleation and growth rates perfomances. As conclusion, different trends of crystallization kinetics are expected regarding the different molecular structure of PLLA in this study.

Table 2. Isothermal crystallization parameters for neat PLLA and chain extended modified PLLAs.

\begin{tabular}{|c|c|c|c|c|c|c|c|c|}
\hline Sample & $\begin{array}{c}\text { Crystallization } \\
\text { Temperature } \\
\left({ }^{\circ} \mathrm{C}\right)\end{array}$ & $\begin{array}{c}t_{c} \\
(\min )\end{array}$ & $\begin{array}{l}\Delta H_{c} \\
(J / g)\end{array}$ & $n$ & $\begin{array}{l}Z \times 10^{3} \\
\left(\min ^{-n}\right)\end{array}$ & $\begin{array}{l}k \times 10^{3} \\
\left(\min ^{-1}\right)\end{array}$ & $\begin{array}{c}t_{1 / 2}{ }^{\mathrm{a}} \\
(\mathrm{min})\end{array}$ & $\begin{array}{c}t_{1 / 2}^{b} \\
(\min )\end{array}$ \\
\hline \multirow{4}{*}{ PLLA0R } & 100 & 8.4 & 19.4 & 2.7 & 6.1 & 151 & 5.7 & 5.7 \\
\hline & 110 & 8.5 & 22.3 & 2.5 & 10.1 & 158 & 5.4 & 5.3 \\
\hline & 120 & 9.5 & 26.4 & 2.6 & 6.1 & 140 & 6.2 & 6.1 \\
\hline & 130 & 15.1 & 30.9 & 2.7 & 1.0 & 77 & 11.2 & 11.2 \\
\hline \multirow{4}{*}{ PLLA0.25R } & 100 & 14.1 & 18.8 & 2.7 & 1.4 & 87 & 10.1 & 9.9 \\
\hline & 110 & 13.5 & 20.7 & 2.8 & 1.2 & 91 & 9.6 & 9.8 \\
\hline & 120 & 16.9 & 26.9 & 2.8 & 0.5 & 69 & 12.7 & 12.8 \\
\hline & 130 & 31.5 & 29.5 & 2.6 & 0.4 & 50 & 17.4 & 18.2 \\
\hline \multirow{4}{*}{ PLLA0.5R } & 100 & 7.5 & 14.3 & 2.5 & 6.7 & 135 & 6.4 & 6.2 \\
\hline & 110 & 7.8 & 17.2 & 2.6 & 6.7 & 146 & 5.9 & 5.8 \\
\hline & 120 & 8.9 & 20.7 & 2.7 & 3.7 & 125 & 6.9 & 7.0 \\
\hline & 130 & 14.5 & 25.6 & 2.7 & 0.9 & 75 & 11.7 & 11.5 \\
\hline \multirow{4}{*}{ PLLA1R } & 100 & 5.2 & 13.4 & 2.7 & 36.9 & 294 & 3.0 & 3 \\
\hline & 110 & 4.1 & 14.8 & 2.8 & 49.8 & 343 & 2.6 & 2.6 \\
\hline & 120 & 4.5 & 18.9 & 2.6 & 60.8 & 341 & 2.5 & 2.6 \\
\hline & 130 & 7.2 & 23.6 & 2.6 & 13.6 & 191 & 4.5 & 4.5 \\
\hline
\end{tabular}

a Obtained from Avrami analysis.

${ }^{\mathrm{b}}$ Directly obtained from the relative crystallinity versus time plot. 
Polarized optical microscopy was employed to determine the influence of primary nucleation and crystal growth on the overall crystallization rate. Spherulitic morphologies of two representative samples (i.e. PLLA0R and PLLA1R) during crystallization at $130{ }^{\circ} \mathrm{C}$ are displayed in Figure 8. Primary nucleation density is clearly greater for the PLLA1R sample as previously predicted considering the nucleation effect caused by the presence of Joncryl. The evolution of the radius of the spherulite with crystallization time (figure 9) was however slower for PLLA1R. Logically its greater molecular weight hindered molecular diffusion to the crystal growth front. Optical analyses confirmed therefore that the increase of crystallization rate was consequence of nucleation. In the same way, the decrease on the crystal growth rate was the prevalent factor for the PLLA0.25R sample that led to a decrease of the overall crystallization rate with respect to that determined for the neat PLLA. Both factors (i.e. nucleation density and crystal growth rate) were perfectly compensated in the case of PLLA0.5R. 

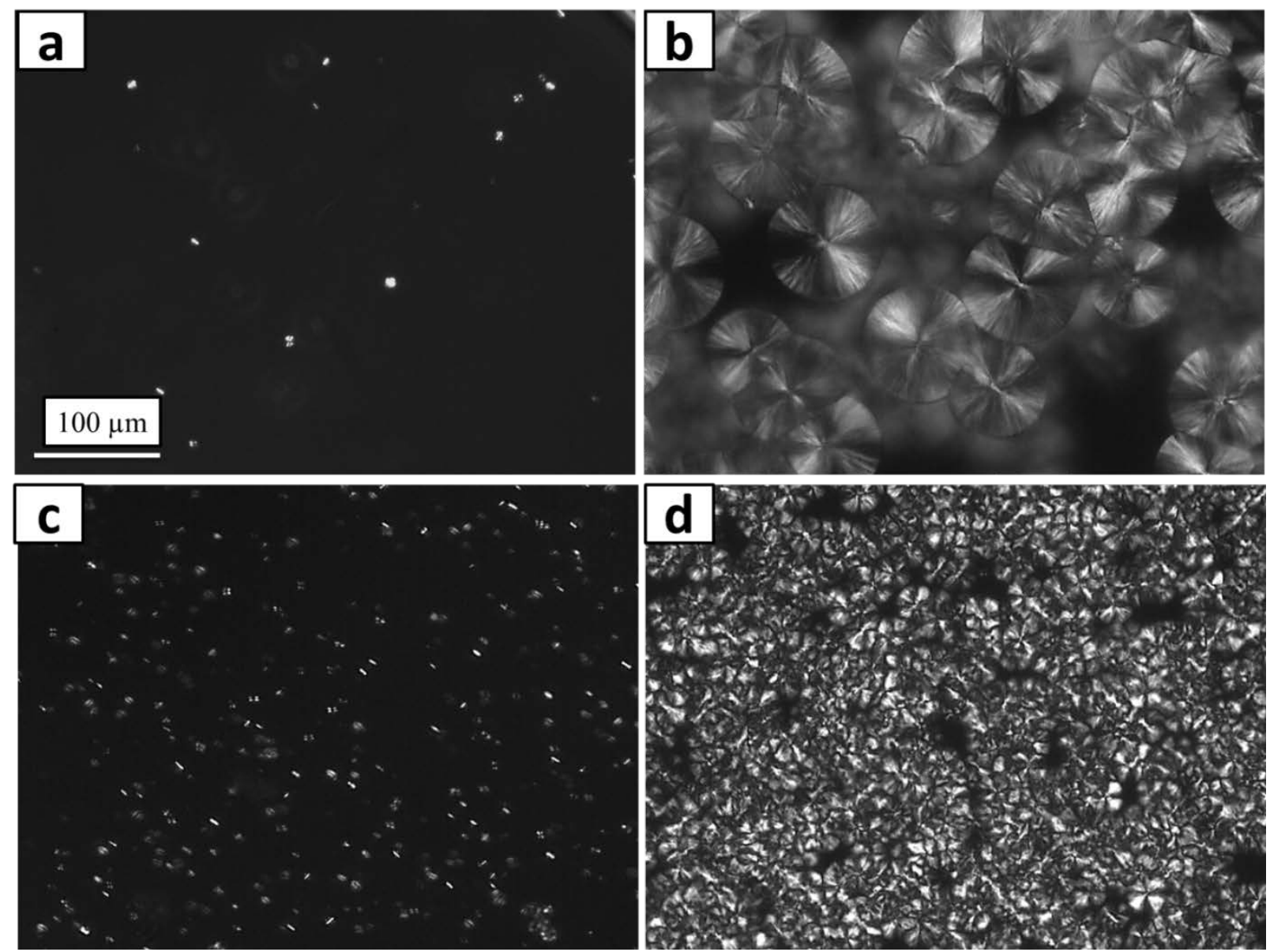

Figure 8. Optical micrographs of PLLA0R (a and b) and PLLA1R (c and d) taken at a temperature of $130{ }^{\circ} \mathrm{C}$ after 1 minute (a and c) and 10 minutes (b and d) of isothermal crystallization.

Figure 9 compares the spherulitic growth rates evaluated for the PLLA0R and PLLA1R samples at various crystallization temperatures (calculation at $100{ }^{\circ} \mathrm{C}$ was not possible due to high number of small spherulites), being clear that the chain extension influenced significantly the spherulite growth rate. In other word, a decrease on the crystallization rate was observed when chain extender was incorporated (in sample PLLA1R). This feature seems an indication of a disturbing effect on the motion of polymer chains, which appear more relevant at the crystallization temperature of $120^{\circ} \mathrm{C}$ (i.e. $5.11 \mu \mathrm{m} / \mathrm{min}$ for sample PLLA0R in comparison with 
$3.45 \mu \mathrm{m} / \mathrm{min}$ for sample PLLA1R) where crystallization becomes limited by the chain transport energy. It is also clear that the effect of chain extension on the crystal growth rate is significant as well as their influence on nucleation. However the nucleation is more effective in crystallization of PLLA with a significant influence in the crystallization kinetics.
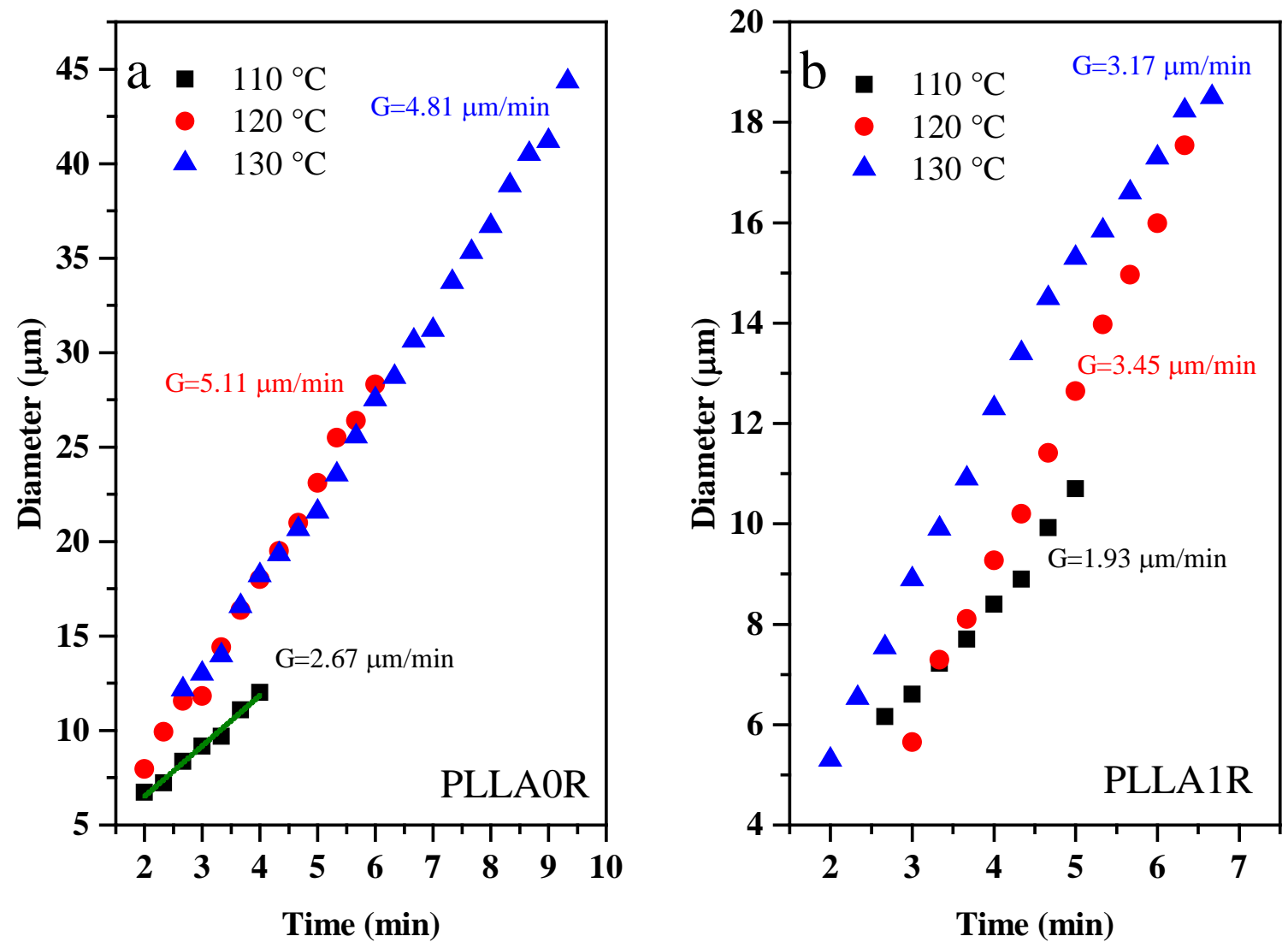

Figure 9. Spherulite diameter as a function of time at different isothermal crystallization temperatures for (a) PLLA0R and (b) PLLA1R. Straight lines are fitted to the experimental data to calculate the growth rate $(G)$ from the slope.

The analysis of the crystallization behavior was also followed under non-isothermal conditions corresponding to cooling rates of 2.5, 5, 7.5 and $10{ }^{\circ} \mathrm{C} / \mathrm{min}$ (Figure 10). Basically, the crystallization peak for each sample moved to lower temperatures and became broader as the 
cooling rate increased. Differences were clear between samples crystallized at low rates (i.e. 2.5 and $5{ }^{\circ} \mathrm{C} / \mathrm{min}$ ) and were less evident at higher rates due to the scarce crystallization. Thermograms showed also a complex peak for PLLA0R and PLLA0.25R at the lowest cooling rate which indicates a fractional crystallization derived from some kind of confinement as reported for PLLA [43, 44].
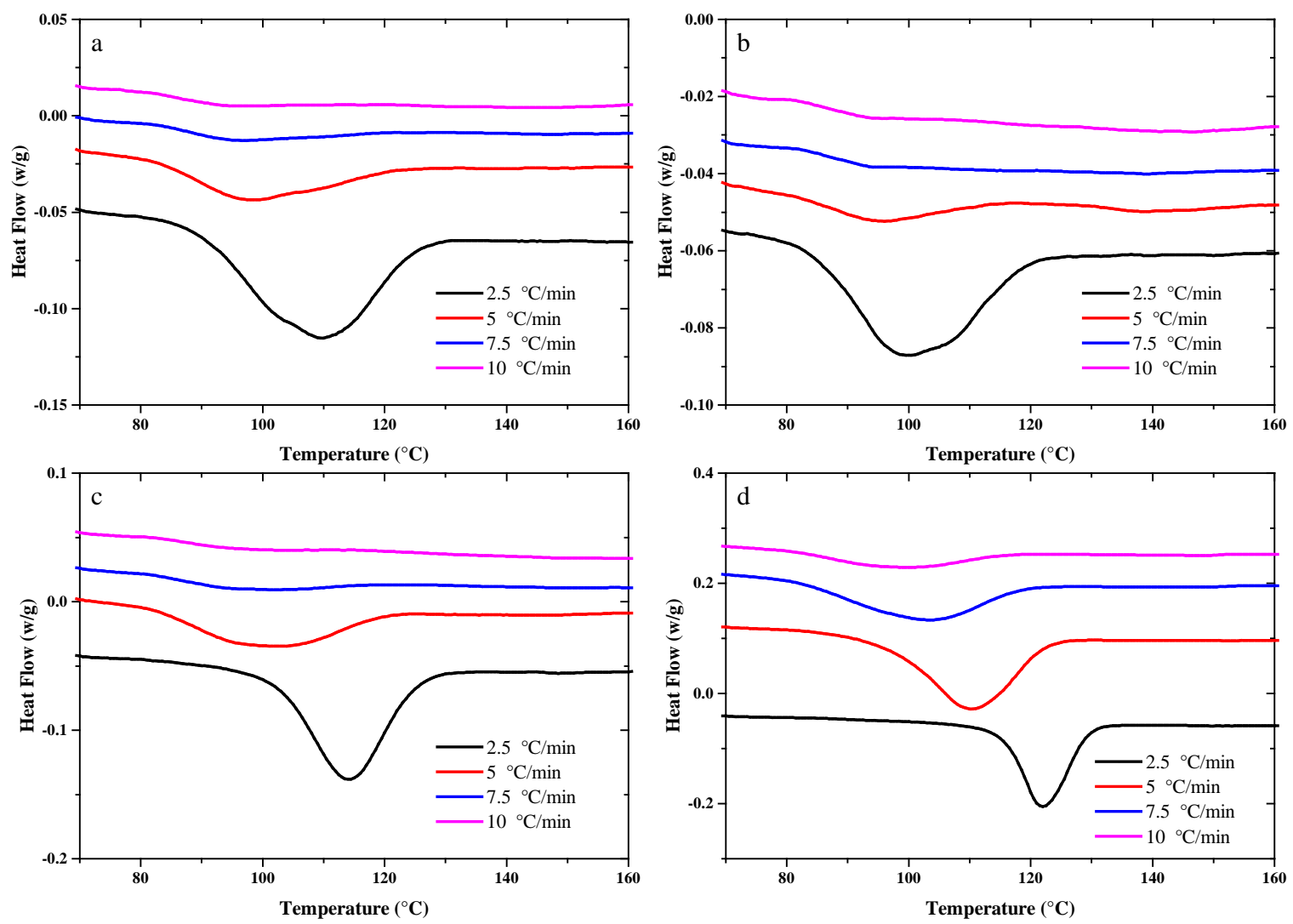

Figure 10. Non-isothermal crystallization at the indicated cooling rates of: a) PLLA0R b) PLLA0.25R, c) PLLA0.5R and d) PLLA1R.

Calorimetric data allowed determining the relative degree of crystallinity at any temperature, $\chi(T)$, for all cooling rates by the expression:

$$
\chi(T)=\frac{\int_{T_{0}}^{T}\left(d H_{c} / d T\right) d T}{\int_{T_{0}}^{T_{\infty}}\left(d H_{c} / d T\right) d T}
$$


where $d H_{c}$ is the enthalpy of crystallization released within an infinitesimal temperature range $d T$, $T_{0}$ denotes the initial crystallization temperature and $T_{\infty}$ is the temperature required to complete the crystallization process. Thus, the denominator corresponds to the overall enthalpy of crystallization for specific heating/cooling conditions. Note that this relative crystallinity is obviously higher than the absolute crystallinity, which is limited by the slow dynamics of polymeric molecular chains. The time dependence of the degree of crystallinity can be derived considering the relationship:

$$
\left(t-t_{0}\right)=\left(T-T_{0}\right) / \phi
$$

where $T_{0}$ is the temperature when crystallization begins $\left(t=t_{0}\right)$ and $\phi$ is the cooling rate.

Figure 11 shows the evolution of the relative crystallinity in function of temperature and time for all samples at the cooling rate of $2.5^{\circ} \mathrm{C} / \mathrm{min}$ where the highest absolute crystallinity was attained. Results clearly demonstrated the influence of the Joncryl content on the crystallization rate, which specifically decreased in the order PLLA1R $>>$ PLLA0.5R $>$ PLLA0R $>>$ PLLA0.25R. This behavior is similar to that observed from isothermal crystallization and demonstrated the nucleation effect caused by a high Joncryl content and the hindered crystallization derived from the existence of branched chains. Nevertheless, it should be pointed out the inversion between the behaviors of PLLA0R and PLLA0.5R. It seems that this feature reflects that PLLA0R follows a complex crystallization behavior where two processes are overlapped, being one of them delayed as a consequence of some degree of confinement caused by the faster crystallization of a polymer fraction. Note also the flatter appearance of the relative crystallinity versus temperature plot of both PLLA0R and PLLA0.25R samples that is consequence of the indicated overlapping. 

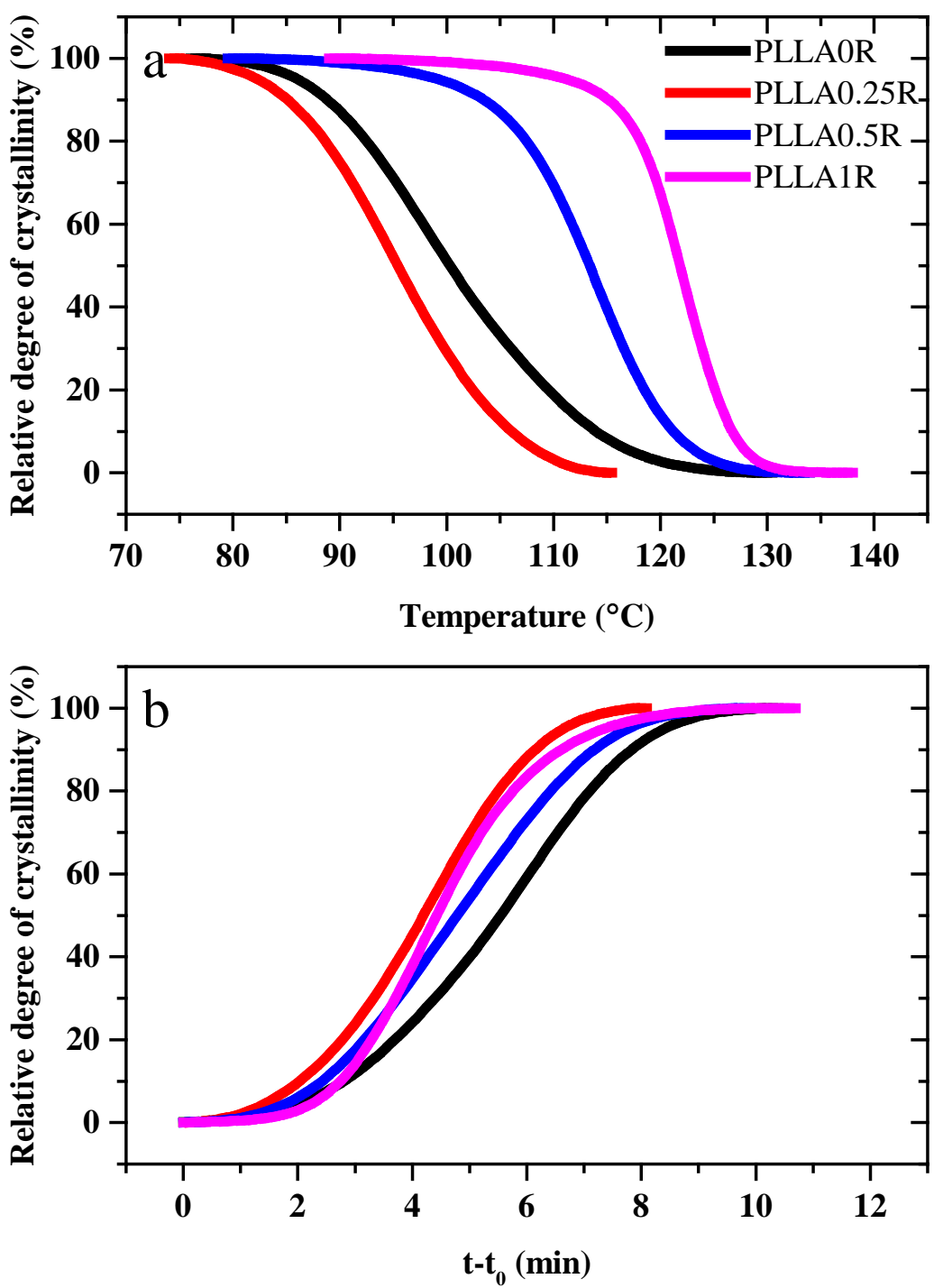

Figure 11. Variation of the relative degree of crystallinity versus time (a) and temperature (b) for the non-isothermal crystallization of the indicated samples at cooling rate of $2.5^{\circ} \mathrm{C} / \mathrm{min}$.

The typical Avrami analysis can also be applied to non-isothermal experiments on the basis of equation 5. Specifically, Figure 12 shows the Avrami plots of the studied samples for a cooling rate of $2.5{ }^{\circ} \mathrm{C} / \mathrm{min}$, while Table 3 summarizes the kinetic parameters deduced from the nonisothermal analysis, including the overall crystallization rate (i.e. $k=Z^{1 / n}$ ). 


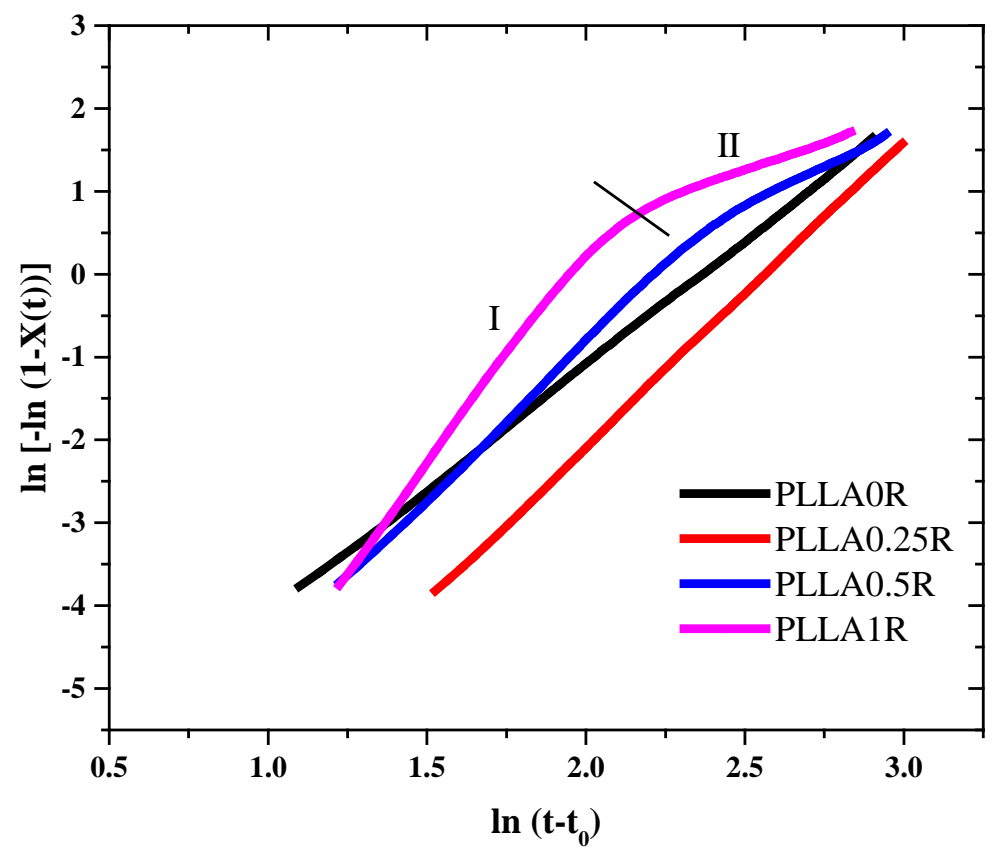

Figure 12. Avrami plots for the non-isothermal crystallization of the indicated samples performed at a cooling rate of $2.5{ }^{\circ} \mathrm{C} / \mathrm{min}$. The two crystallization regions are indicated for sample PLLA1R (i.e. I and II).

Table 3. Kinetic parameters for the non-isothermal crystallization of neat PLLA and samples loaded with different percentages of Joncryl.

\begin{tabular}{|c|c|c|c|c|c|c|c|c|c|}
\hline Sample & $\begin{array}{c}\text { Cooling rate } \\
\left({ }^{\circ} \mathrm{C} / \mathrm{min}\right)\end{array}$ & $\begin{array}{c}T_{c} \\
\left({ }^{\circ} C\right)\end{array}$ & $\begin{array}{l}\Delta H_{c} \\
(J / g)\end{array}$ & $n_{1}$ & $n_{2}$ & $\begin{array}{c}Z_{1} \times 10^{4} \\
\left(\min ^{-n}\right)\end{array}$ & $\begin{array}{l}k_{1} \times 10^{3} \\
\left(\min ^{-1}\right)\end{array}$ & $\begin{array}{c}Z_{2} \times 10^{4} \\
\left(\min ^{-n}\right)\end{array}$ & $\begin{array}{l}k_{2} \times 10^{3} \\
\left(\min ^{-1}\right)\end{array}$ \\
\hline \multirow[t]{2}{*}{ PLLA0R } & 2.5 & 110 & 31.1 & 3.0 & - & 8.6 & 95 & - & - \\
\hline & 5 & 98 & 6.0 & 3.0 & - & 41.2 & 160 & - & - \\
\hline \multirow[t]{2}{*}{ PLLA0.25R } & 2.5 & 101 & 16.0 & 3.7 & - & 0.7 & 76 & - & - \\
\hline & 5 & 96 & 1.4 & 2.9 & - & 31.3 & 137 & & - \\
\hline \multirow[t]{2}{*}{ PLLA0.5R } & 2.5 & 114 & 32.5 & 3.8 & 1.9 & 2.2 & 110 & 213 & 128 \\
\hline & 5 & 101 & 8.7 & 2.9 & - & 79.1 & 188 & - & - \\
\hline \multirow[t]{2}{*}{ PLLA1R } & 2.5 & 122 & 36.1 & 4.8 & 1.3 & 0.8 & 139 & 1212 & 207 \\
\hline & 5 & 110 & 28.1 & 3.7 & 2.6 & 24.8 & 197 & 170 & 209 \\
\hline
\end{tabular}


Note that samples with a high Joncryl content showed a significant secondary crystallization and consequently the corresponding parameters have also been determined.

The following points can be deduced from the Avrami analysis under non-isothermal conditions: a) The Avrami exponent takes higher values than expected considering crystal growth dimensionality and nucleation type and consequently loses its physical sense. In fact, the literature reported the values for PLLA were in the range of 2-5.4 [41]. Nevertheless, the deduced exponents obey to a mathematical fitting and are useful for comparative purposes. As a general trend it is observed that the exponent decreased with the cooling rate suggesting an increase of the heterogeneous and instantaneous nucleation. Logically, exponents corresponding to the secondary crystallization are lower as consequence of the decrease of crystal dimensionality caused by space constrictions. The exponent seems also to depend on the molecular weight and structure, being observed a decrease in the order: PLLA1R > PLLA0.5R PLLA0.25R > PLLA0R. It seems that the more dynamical heterogeneity of polymer chains in PLLA1R resulted in a different crystallization mechanism.

b) The Avrami plots showed a clear secondary crystallization process for PLLA1R and PLLA0.5R samples, being determined a clear decrease of the corresponding exponent $\left(n_{2}\right)$.

c) The overall crystallization rate logically increased with the cooling rate and depended on the chain extender content according to the previously indicated order: PLLA1R > PLLA0.5R > PLLA0R > PLLA0.25R.

Crystallization enthalpies are also summarized in Table 3. Interestingly, these values followed the order: PLLA1R > PLLA0.5R > PLLA0R > PLLA0.25R, which means a great correlation with the evaluated crystallization rates. Note also the dramatic decrease on the enthalpy when the cooling rate increased up to $5{ }^{\circ} \mathrm{C} / \mathrm{min}$. In this case, only PLLA1R rendered a significant 
crystallization peak enthalpy probably as a consequence of the nucleation effect and the still fast crystallization. In other words, samples with a low nucleation crystallized too much slowly to follow a high cooling rate process.

\section{Conclusions}

In the present study, the effect of reactive melt mixing of PLLA with epoxy-based chain extender on the derived rheological and crystallization behavior was investigated. The torque-time plot showed that the continuous degradation of PLLA was compensated during reactive mixing by the addition of Joncryl and that a gradual increase of torque could be achieved the increasing Joncryl concentration. The GPC analysis demonstrated the increase of both molecular weight and PDI and showed a new GPC peak associated to the chain extension reaction. Rheological analysis revealed that increasing the concentration of Joncryl leaded to an increase of the modulus and viscosity, which supported the improvement of melt strength during the reactive melt processing. Van Gurp-Palmen plots and relaxation spectra substantiated that chain topology of PLLA during the reactive mixing changed and specifically long-chain branches were formed. The isothermal crystallization results from both calorimetric and optical microscopy observations revealed that the increase of the molecular weight associated to a significant chain extender reaction facilitated the primary nucleation and increased the overall crystallization rate constant. By contrast, the addition of low percentages of Joncryl led to a decrease of the crystallization rate since the predominant effect was consequence of the presence of branches that hindered the molecular ordering process in this case. Similar results were also deduced from non-isothermal crystallization studies, although small differences were found when the behavior of neat PLLA and the sample containing 0.5 wt-\% of Joncryl were compared, being highlighted the influence of processing conditions (i.e. isothermal and non-isothermal). 


\section{Acknowledgements}

The authors would like to thank Iran National Science Foundation: INSF for the financial support (97009359). J.P. and L.F. are grateful to support from MINECO and FEDER (RTI2018101827-B-I00) and the Generalitat de Catalunya (2017SGR373).

\section{References}

[1] M. Eriksen, N. Maximenko, M. Thiel, A. Cummins, G. Lattin, S. Wilson, J. Hafner, A. Zellers, S. Rifman, Plastic pollution in the South Pacific subtropical gyre, Marine Pollution Bulletin, 68 (2013) 71-76.

[2] J.G.B. Derraik, The pollution of the marine environment by plastic debris: a review, Marine Pollution Bulletin, 44 (2002) 842-852.

[3] M. Rinaudo, Chitin and chitosan: Properties and applications, Progress in Polymer Science, 31 (2006) 603-632.

[4] F. Xie, E. Pollet, P.J. Halley, L. Avérous, Starch-based nano-biocomposites, Progress in Polymer Science, 38 (2013) 1590-1628.

[5] S. Wang, A. Lu, L. Zhang, Recent advances in regenerated cellulose materials, Progress in Polymer Science, 53 (2016) 169-206.

[6] K. Hamad, M. Kaseem, M. Ayyoob, J. Joo, F. Deri, Polylactic acid blends: The future of green, light and tough, Progress in Polymer Science, 85 (2018) 83-127.

[7] L.T. Lim, R. Auras, M. Rubino, Processing technologies for poly(lactic acid), Progress in Polymer Science, 33 (2008) 820-852.

[8] G. Perego, G.D. Cella, C. Bastioli, Effect of molecular weight and crystallinity on poly(lactic acid) mechanical properties, 59 (1996) 37-43.

[9] V. Arias, K. Odelius, A. Höglund, A.-C. Albertsson, Homocomposites of Polylactide (PLA) with Induced Interfacial Stereocomplex Crystallites, ACS Sustainable Chemistry \& Engineering, 3 (2015) 2220-2231.

[10] N. Najafi, M.C. Heuzey, P.J. Carreau, Polylactide (PLA)-clay nanocomposites prepared by melt compounding in the presence of a chain extender, Composites Science and Technology, 72 (2012) 608615.

[11] R. Datta, M. Henry, Lactic acid: recent advances in products, processes and technologies - a review, 81 (2006) 1119-1129.

[12] H. Tsuji, H. Daimon, K. Fujie, A New Strategy for Recycling and Preparation of Poly(l-lactic acid): Hydrolysis in the Melt, Biomacromolecules, 4 (2003) 835-840.

[13] S.-Y. Zhou, H.-D. Huang, X. Ji, D.-X. Yan, G.-J. Zhong, B.S. Hsiao, Z.-M. Li, Super-Robust Polylactide Barrier Films by Building Densely Oriented Lamellae Incorporated with Ductile in Situ Nanofibrils of Poly(butylene adipate-co-terephthalate), ACS Applied Materials \& Interfaces, 8 (2016) 8096-8109.

[14] O. Yousefzade, J.M. Ugartemendia, L. Sangroniz, R. Hernandez, J. Puiggali, H. Garmabi, Reactive melt processing of poly (L-lactide) in the presence of thermoplastic polyurethane and carboxylated carbon nanotubes, Journal of Materials Science, (2019), https://doi.org/10.1007/s10853-019-03889-8.

[15] S. Barrau, C. Vanmansart, M. Moreau, A. Addad, G. Stoclet, J.M. Lefebvre, R. Seguela, Crystallization Behavior of Carbon Nanotube-Polylactide Nanocomposites, Macromolecules, 44 (2011) 6496-6502.

[16] D. Wu, Y. Cheng, S. Feng, Z. Yao, M. Zhang, Crystallization Behavior of Polylactide/Graphene Composites, Industrial \& Engineering Chemistry Research, 52 (2013) 6731-6739. 
[17] X. Meng, G. Shi, W. Chen, C. Wu, Z. Xin, T. Han, Y. Shi, Structure effect of phosphite on the chain extension in PLA, Polymer Degradation and Stability, 120 (2015) 283-289.

[18] Y. Ahmadzadeh, A. Babaei, A. Goudarzi, Assessment of localization and degradation of ZnO nanoparticles in the PLA/PCL biocompatible blend through a comprehensive rheological characterization, Polymer Degradation and Stability, 158 (2018) 136-147.

[19] N. Najafi, M.C. Heuzey, P.J. Carreau, P.M. Wood-Adams, Control of thermal degradation of polylactide (PLA)-clay nanocomposites using chain extenders, Polymer Degradation and Stability, 97 (2012) 554-565.

[20] O. Yousefzade, H. Garmabi, J. Puiggali, Cooperative rearranging region and dynamical heterogeneity of nanocomposites in poly(I-lactide) and functionalized carbon nanotubes systems, Thermochimica Acta, 667 (2018) 35-41.

[21] O. Yousefzade, S. Valenti, J. Puiggalí, H. Garmabi, R. Macovez, Segmental relaxation and partial crystallization of chain-extended Poly(I-lactic acid) reinforced with carboxylated carbon nanotube, Journal of Polymer Science Part B: Polymer Physics, 57 (2019) 222-233.

[22] O. Yousefzade, L. Franco, M. Nami, J. Puiggali, H. Garmabi, Nanocomposites based on chain extended poly(l-lactic acid)/carboxylated carbon nanotubes: Crystallization kinetics and lamellar morphology, Journal of Composite Materials, 0 (2019).

[23] H. Ebrahimi, F. Sadat Afshar Najafi, I. Shahabad, H. Garmabi, A response surface study on microstructure and mechanical properties of poly(lactic acid)/ thermoplastic starch/nanoclay nanocomposites, 2015.

[24] R. Al-Itry, K. Lamnawar, A. Maazouz, Improvement of thermal stability, rheological and mechanical properties of PLA, PBAT and their blends by reactive extrusion with functionalized epoxy, Polymer Degradation and Stability, 97 (2012) 1898-1914.

[25] F.D. Kopinke, K. Mackenzie, Mechanistic aspects of the thermal degradation of poly(lactic acid) and poly( $\beta$-hydroxybutyric acid), Journal of Analytical and Applied Pyrolysis, 40-41 (1997) 43-53.

[26] A. Södergård, J.H. Näsman, Stabilization of poly(l-lactide) in the melt, Polymer Degradation and Stability, 46 (1994) 25-30.

[27] M. Takamura, T. Nakamura, T. Takahashi, K. Koyama, Effect of type of peroxide on cross-linking of poly(I-lactide), Polymer Degradation and Stability, 93 (2008) 1909-1916.

[28] T.M. Quynh, H. Mitomo, L. Zhao, M. Tamada, Properties of a poly(L-lactic acid)/poly(D-lactic acid) stereocomplex and the stereocomplex crosslinked with triallyl isocyanurate by irradiation, 110 (2008) 2358-2365.

[29] P. Rytlewski, R. Malinowski, K. Moraczewski, M. Żenkiewicz, Influence of some crosslinking agents on thermal and mechanical properties of electron beam irradiated polylactide, Radiation Physics and Chemistry, 79 (2010) 1052-1057.

[30] R. Al-Itry, K. Lamnawar, A. Maazouz, Reactive extrusion of PLA, PBAT with a multi-functional epoxide: Physico-chemical and rheological properties, European Polymer Journal, 58 (2014) 90-102.

[31] P. Tiwary, M. Kontopoulou, Rheological characterization of long-chain branched poly(lactide) prepared by reactive extrusion in the presence of allylic and acrylic coagents, Journal of Rheology, 62 (2018) 1071-1082.

[32] O. Yousefzade, H. Garmabi, J. Puiggali, M. Heydarnejad Moghadam, Rigid amorphous phase and constrained polymer chains in poly(L-lactide) nanocomposites with carboxylated carbon nanotubes prepared via reactive melt mixing, 39 (2018) E1280-E1293.

[33] D. Yuan, K. Chen, C. Xu, Z. Chen, Y. Chen, Crosslinked bicontinuous biobased PLA/NR blends via dynamic vulcanization using different curing systems, Carbohydrate Polymers, 113 (2014) 438-445.

[34] V. Kontogiorgos, Calculation of relaxation spectra from mechanical spectra in MATLAB, Polymer Testing, 29 (2010) 1021-1025. 
[35] J. Jeddi, O. Yousefzade, A. Babaei, S. Ghanbar, A. Rostami, Morphology, microstructure and rheological properties of SAN (styrene-acrylonitrile)/EPDM (ethylene-propylene-diene monomer) nanocomposites: Investigating the role of organoclay type and order of mixing, Materials Chemistry and Physics, 187 (2017) 191-202.

[36] P.C. Hansen, REGULARIZATION TOOLS: A Matlab package for analysis and solution of discrete illposed problems, Numerical Algorithms, 6 (1994) 1-35.

[37] S.H. Tabatabaei, P.J. Carreau, A. Ajji, Rheological properties of blends of linear and long-chain branched polypropylenes, Polymer Engineering \& Science, 50 (2010) 191-199.

[38] S. Trinkle, P. Walter, C. Friedrich, Van Gurp-Palmen Plot II - classification of long chain branched polymers by their topology, Rheologica Acta, 41 (2002) 103-113.

[39] M. Avrami, Granulation, Phase Change, and Microstructure Kinetics of Phase Change. III, The Journal of Chemical Physics, 9 (1941) 177-184.

[40] M. Nofar, A. Tabatabaei, C.B. Park, Effects of nano-/micro-sized additives on the crystallization behaviors of PLA and PLA/CO2 mixtures, Polymer, 54 (2013) 2382-2391.

[41] C. Kim Piew, S.N. Gan, K.K. Chee, Determination of avrami exponent by differential scanning calorimetry for non-isothermal crystallization of polymers, Polymer, 40 (1999) 253-259.

[42] M. Nofar, W. Zhu, C.B. Park, J. Randall, Crystallization Kinetics of Linear and Long-Chain-Branched Polylactide, Industrial \& Engineering Chemistry Research, 50 (2011) 13789-13798.

[43] D. Zhou, J. Sun, J. Shao, X. Bian, S. Huang, G. Li, X. Chen, Unusual crystallization and melting behavior induced by microphase separation in MPEG-b-PLLA diblock copolymer, Polymer, 80 (2015) 123129.

[44] L. Han, P. Pan, G. Shan, Y. Bao, Stereocomplex crystallization of high-molecular-weight poly(I-lactic acid)/poly(d-lactic acid) racemic blends promoted by a selective nucleator, Polymer, 63 (2015) 144-153. 